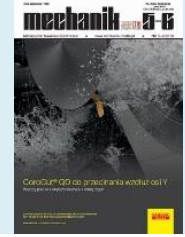

Authors: Marcin Szuster, Paweł Obal

Title of article: „Dynamika mobilnego robota transportowego" ("The dynamics of a mobile transport robot”)

Mechanik, Vol. 91, No. 5-6 (2018): pages 390-395

DOI: https://doi.org/10.17814/mechanik.2018.5-6.51

\title{
The dynamics of a mobile transport robot
}

\section{Dynamika mobilnego robota transportowego}

\section{MARCIN SZUSTER PAWEŁ OBAL *}

The article presents the construction of a mobile transport robot which is a forklift model, used for laboratory testing of control methods for complex dynamic objects in changing operating conditions. The robot dynamics is calculated using Lagrange equations of the 2 nd type with multipliers. The results of solving the inverse dynamics problem were presented using the robot's trajectory which consists of stages of movement typical for transport tasks performed by forklift.

KEYWORDS: 3-wheeled mobile robot, mobile robot dynamics

Synthesis of many types of control algorithms requires knowledge of the dynamics model of the controlled object [2, 3]. For this purpose, models of varying complexity are used, usually taking into account the most important phenomena occurring during the movement of the object, which simplifies the calculation. Many mathematical formalisms are known to enable the synthesis of dynamic equations of motion of mechanical objects [8]. In the case of mobile circular robots, which are nonholonomic systems, the second kind of Lagrange equations with multipliers and Maggi's equations are often used [3, 4, 7]. From the Lagrange equations of the second type, dynamic motion equations are obtained, which allow to solve the simple and inverse task of dynamics. In contrast to Maggi's formalism, this method allows the determination of Lagrange multipliers, which in the case of mobile circular robots assume the form of the values of dry friction forces acting at the contact points of the robot's wheels with the road.

The work uses the second kind of Lagrange equation to describe the dynamics of a mobile transport robot. Simulation studies have been carried out on the basis of this description.

\section{Construction of a mobile transport robot}

The frame of the mobile transport robot (MRT) is made of aluminum mounting profiles from Bosch Rexroth. In addition to the assembly profiles, the manufacturer also offers various types of connecting and supporting elements - both rigid and movable. CAD MRT visualization is shown in fig. 1. MRT consists of a chassis and a lifting unit that allows transport of loads. The chassis is built from a frame supported by two free front wheels and a driven rear wheel mounted in a movable steering unit.

Robotic DC motors (BLDC) [1] were used to drive the robot mobile platform. The forklift movement is provided by two line modules from WObit, equipped with DC motors. The MRT design is modeled on three-wheeled lift truck solutions with a driven and steered rear wheel. The robot makes it possible to transport loads of up to $20 \mathrm{~kg}$.

\section{Dynamic traffic equations}

The Lagrange equations of the second type with multipliers were used to describe the MRT dynamics. The MRT model [9] shown in fig. 2 was adopted, consisting of: frame 5, two support wheels 1 and 2, driving wheel 3 attached to the steering wheel 4 and fork lift 6 . Wheel 3 and steering wheel 4 are part of the driving-steering unit. This assembly rotates relative to the frame 5 about the axis $z_{4}$ by an angle $\varphi$. The frame rests on support wheels 1 and 2 , which can make free rotation about the axis with directions permanently associated with the frame of the robot, perpendicular to the plane of longitudinal symmetry of the frame. All wheels are made of hard plastic coated with rigid rubber. The radii of circles 1 and 2 are the same $\left(r_{1}=r_{2}\right)$, while the radius $r_{3}$ of the

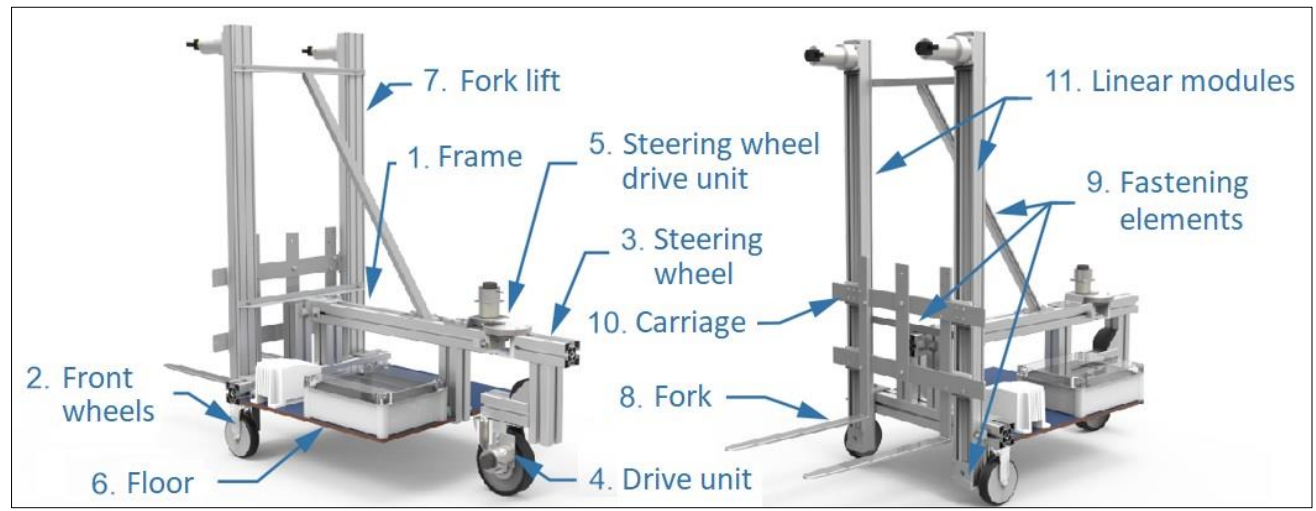

Fig. 1. Visualization of the CAD model of a mobile transport robot

\footnotetext{
* Dr inż. Marcin Szuster (mszuster@prz.edu.pl), mgr inż. Paweł Obal (p.obal@prz.edu.pl) - Katedra Mechaniki Stosowanej i Robotyki, Poli-
} technika Rzeszowska 
wheel 3 is larger. The presented model has been reduced to the model in which the free wheels 1 and 2 were replaced by the free $1 z$ substitute wheel. The rotation angle of the replacement wheel is marked as $\alpha_{z}$.

The robot's movement is described by means of a reduced form of equations of nonholonomic constraints. This made it possible to determine the driving moments and Lagrange multipliers $[3,5,6]$, which are the tangent components of the ground reaction forces on the wheels, i.e. the dry friction forces at the contact point of the replacement wheel $1 z$ and the drive wheel 3 with the ground. Equations have the form:

$$
\begin{gathered}
\dot{x}_{\mathrm{A}}-r_{\mathrm{z}} \dot{\alpha}_{\mathrm{z}} \cos \beta=0 \\
\dot{y}_{\mathrm{A}}-r_{\mathrm{z}} \dot{\alpha}_{\mathrm{z}} \sin \beta=0 \\
\dot{x}_{\mathrm{A}}+l \dot{\beta} \sin \beta-\dot{\alpha}_{3} r_{3} \cos (\varphi+\beta)=0 \\
\dot{y}_{A}-l \dot{\beta} \cos \beta-\dot{\alpha}_{3} r_{3} \sin (\varphi+\beta)=0
\end{gathered}
$$

where: $\dot{x}_{A}, \dot{y}_{A}$ - projections of the velocity vector of the A point associated with the MRT frame, $\dot{\alpha}_{\mathrm{z}}-$ angular velocity of the free replacement wheel, $\dot{\alpha}_{3}-$ angular velocity of the drive wheel, $\varphi$ - steering wheel rotation angle with respect to the robot frame, $\beta$-momentary rotation angle of the robot frame.

The first two equations are the projections of the velocity vector of the point of contact of the replacement wheel $1 z$ with the roadway on the axes of the system $x y$.

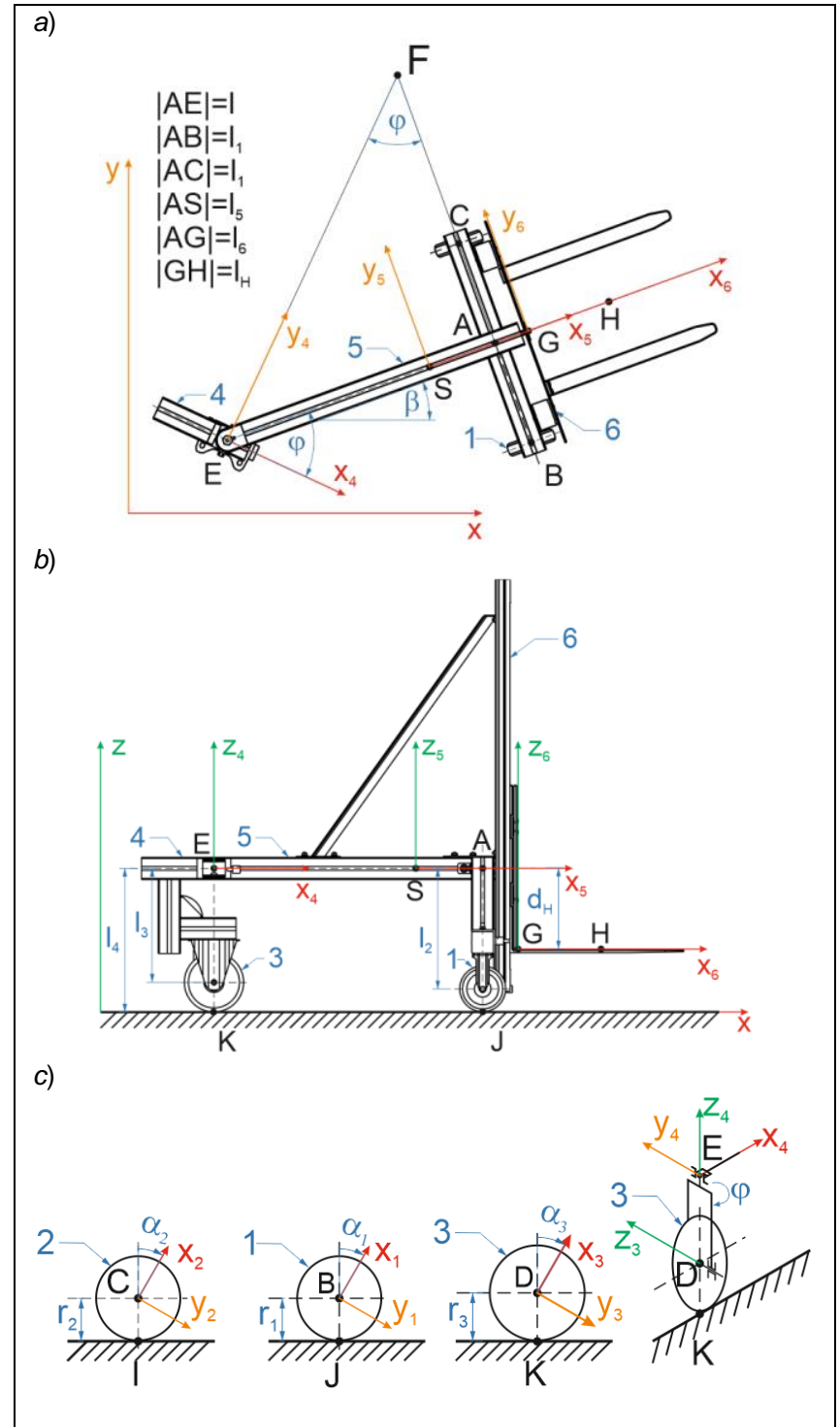

Fig. 2. MRT scheme: a) top view, b) right view, c) models of road wheels and driving-steering unit
The next two are the projections of the velocity vector of the point of contact between the drive wheel and the roadway on the axes of the system $x y$.

The mobile robot platform under study is a two-degree system of freedom, because the two variables in the equations are independent variables.

The Lagrange equations of the second type, used to determine the dynamic equations of motion of the nonholonomic system, have the form:

$$
\frac{\mathrm{d}}{\mathrm{d} t}\left(\frac{\partial E}{\partial \dot{\mathbf{q}}}\right)^{\mathrm{T}}-\left(\frac{\partial E}{\partial \mathbf{q}}\right)^{\mathrm{T}}=\mathbf{Q}+\mathbf{J}^{\mathrm{T}}(\mathbf{q}) \boldsymbol{\lambda}
$$

where: $\mathbf{q}=\left[x_{\mathrm{A}}, y_{\mathrm{A}}, \beta, \alpha_{\mathrm{Z}}, \alpha_{3}, \varphi\right]^{\mathrm{T}}-$ vector of generalized coordinates, $E$ - kinetic energy of the system, $\mathbf{Q}$ - vector of generalized forces, $\mathbf{J}(\mathbf{q})$ - Jacobian, $\boldsymbol{\Lambda}$ - vector of Lagrange multipliers.

The kinetic energy of the system was determined as the sum of kinetic energy of individual structural elements:

$$
E=E_{1}+E_{2}+E_{3}+E_{4}+E_{5}+E_{6}
$$

Index numbers correspond to the numbering of structure elements in fig. 2. Particular kinetic energy equations have the form:

$$
\begin{gathered}
E_{1}=\frac{1}{2} m_{1} v_{\mathrm{B}}^{2}+\frac{1}{2} I_{\mathrm{z} 1} \dot{\alpha}_{1}^{2}+\frac{1}{2} I_{\mathrm{x} 1} \dot{\beta}^{2} \\
E_{2}=\frac{1}{2} m_{2} v_{\mathrm{C}}^{2}+\frac{1}{2} I_{\mathrm{z} 2} \dot{\alpha}_{2}^{2}+\frac{1}{2} I_{\mathrm{x} 2} \dot{\beta}^{2} \\
E_{3}=\frac{1}{2} m_{3} v_{\mathrm{D}}^{2}+\frac{1}{2} I_{\mathrm{z} 3} \dot{\alpha}_{3}^{2}+\frac{1}{2} I_{\mathrm{x} 3}(\dot{\beta}+\dot{\varphi})^{2} \\
E_{4}=\frac{1}{2} m_{4} v_{\mathrm{E}}^{2}+\frac{1}{2} I_{\mathrm{z} 4}(\dot{\beta}+\dot{\varphi})^{2} \\
E_{5}=\frac{1}{2} m_{5} v_{\mathrm{S}}^{2}+\frac{1}{2} I_{\mathrm{z} 5} \dot{\beta}^{2} \\
E_{5}=\frac{1}{2} m_{6} v_{\mathrm{G}}^{2}+\frac{1}{2} I_{\mathrm{z} 6} \dot{\beta}^{2}
\end{gathered}
$$

where: $m_{1}, m_{2}, m_{3}, m_{4}, m_{5}, m_{6}-$ masses of individual solids; $v_{\mathrm{B}}, v_{\mathrm{C}}, v_{\mathrm{D}}, v_{\mathrm{E}}, v_{\mathrm{S}}, v_{\mathrm{G}}$ - velocity vector values of the respective points; $I_{x 1}, l_{x 2}, l_{x 3}, I_{z 1}, I_{z 2}, I_{z 3}, I_{z 4}, l_{z 5}, l_{z 6}$ - mass moments of inertia of individual solids relative to the respective axes of coordinate systems associated with these solids.

The dependencies describing the relationship of the angular velocity of the $1 z$ replacement wheel with the speed of the support wheels 1 and 2 were determined from the velocity distribution of points $A, B$ and $C$ :

$$
\begin{aligned}
& \dot{\alpha}_{1}=\dot{\alpha}_{\mathrm{Z}}+\frac{l_{1}}{r_{\mathrm{Z}}} \dot{\beta} \\
& \dot{\alpha}_{2}=\dot{\alpha}_{\mathrm{Z}}-\frac{l_{1}}{r_{\mathrm{Z}}} \dot{\beta}
\end{aligned}
$$

where: $r_{1}=r_{2}=r_{\mathrm{Z}}-$ radii of individual circles, $l_{1}-$ distance of points $B$ and $C$ from point $A$.

Kinematic equations (1) can be saved in the form of Jacobian:

$$
\mathbf{J}(\mathbf{q}) \dot{\mathbf{q}}=0
$$

where:

$$
\mathbf{J}(\mathbf{q})=\left[\begin{array}{cccccc}
1 & 0 & 0 & -r_{\mathrm{z}} \cos \beta & 0 & 0 \\
0 & 1 & 0 & -r_{\mathrm{z}} \sin \beta & 0 & 0 \\
1 & 0 & l \sin \beta & 0 & -r_{3} \cos (\beta+\varphi) & 0 \\
0 & 1 & -l \cos \beta & 0 & -r_{3} \sin (\beta+\varphi) & 0
\end{array}\right]
$$


After determining the second type of Lagrange equations and performing a series of operations and mathematical transformations, a system of differential equations of motion of the MRT model was obtained:

$$
\begin{aligned}
& {\left[m_{1}+m_{2}+m_{3}+m_{4}+m_{5}+m_{6}\right] \ddot{x}_{\mathrm{A}}+} \\
& +\left(m_{1}-m_{2}\right) l_{1}\left(\cos (\beta) \ddot{\beta}-\sin (\beta) \dot{\beta}^{2}\right)+ \\
& +\left[\left(m_{3}+m_{4}\right) l+m_{5} l_{3}-m_{6} l_{6}\right]\left(\sin (\beta) \ddot{\beta}+\cos (\beta) \dot{\beta}^{2}\right)= \\
& =-\lambda_{\mathrm{z} 1}+\lambda_{3} \\
& {\left[m_{1}+m_{2}+m_{3}+m_{4}+m_{5}+m_{6}\right] \ddot{y}_{\mathrm{A}}+} \\
& +\left(m_{1}-m_{2}\right) l_{1}\left(\sin (\beta) \ddot{\beta}+\cos (\beta) \dot{\beta}^{2}\right)+ \\
& -\left[\left(m_{3}+m_{4}\right) l+m_{5} l_{3}-m_{6} l_{6}\right]\left(\cos (\beta) \ddot{\beta}-\sin (\beta) \dot{\beta}^{2}\right)= \\
& =-\lambda_{\mathrm{z} 2}+\lambda_{4} \\
& {\left[\left(m_{1}+m_{2}\right) l_{1}^{2}+\left(m_{3}+m_{4}\right) l^{2}+m_{5} l_{5}^{2}+m_{6} l_{6}^{2}+I_{\mathrm{x} 1}+I_{\mathrm{x} 2}+\right.} \\
& \left.+I_{\mathrm{x} 3}+I_{\mathrm{z} 4}+I_{\mathrm{z} 5}+I_{\mathrm{z} 6}+\frac{l_{1}^{2}}{r_{\mathrm{z}}^{2}}\left(I_{\mathrm{z} 1}+I_{\mathrm{z} 2}\right)\right] \ddot{\beta}+\left(I_{\mathrm{x} 3}+I_{\mathrm{z} 4}\right) \ddot{\varphi}+ \\
& +\left(I_{\mathrm{z} 1}-I_{\mathrm{z} 2}\right) \frac{l_{1}}{r_{\mathrm{z}}} \ddot{\alpha}_{\mathrm{z}}+\left(m_{1}-m_{2}\right) l_{1}\left(\ddot{x}_{\mathrm{A}} \cos \beta+\ddot{y}_{\mathrm{A}} \sin \beta\right)+ \\
& -\left[\left(m_{3}+m_{4}\right) l+m_{5} l_{3}-m_{6} l_{6}\right]\left(-\ddot{x}_{\mathrm{A}} \sin \beta+\ddot{y}_{\mathrm{A}} \cos \beta\right)= \\
& =M_{\mathrm{S}}-M_{\mathrm{O}} \operatorname{sgn}(\dot{\varphi})+\left(\lambda_{3} \sin \beta-\lambda_{4} \cos \beta\right) l \\
& \left(I_{\mathrm{z} 1}+I_{\mathrm{zz} 2}\right) \ddot{\alpha}_{\mathrm{z}}+\left(I_{\mathrm{z} 1}-I_{\mathrm{z} 2}\right) \frac{l_{1}}{r_{\mathrm{z}}} \ddot{\beta}=-N_{1} f_{1}-N_{2} f_{2}+ \\
& +r_{\mathrm{z}}\left(\lambda_{\mathrm{z} 1} \cos \beta+\lambda_{\mathrm{z} 2} \sin \beta\right) \\
& I_{\mathrm{z} 3} \ddot{\alpha}_{3}=M_{\mathrm{N}}-N_{3} f_{3}-\lambda_{3} r_{3} \cos (\beta+\varphi)-\lambda_{4} r_{3} \sin (\beta+\varphi) \\
& \left(I_{\mathrm{x} 3}+I_{\mathrm{z} 4}\right)(\ddot{\beta}+\ddot{\varphi})=M_{\mathrm{S}}-\mathrm{M}_{\mathrm{O}} \operatorname{sgn}(\dot{\varphi})
\end{aligned}
$$

where: $\lambda_{z 1}, \lambda_{z 2}, \lambda_{3}, \lambda_{4}$ - Lagrange multipliers, being equivalents of the dry friction components at the contact point of the replacement wheel with the ground on the $x$-axis $\left(\lambda_{z 1}\right)$ and $y$-axis $\left(\lambda_{z 2}\right)$ and at the point of contact of the drive wheel with the ground the directions of the $x$-axis $\left(\lambda_{3}\right)$ and the $y$-axis $\left(\lambda_{4}\right) ; M_{N}$ - wheel drive torque $3 ; M_{\mathrm{S}}$ - steering torque of the steering wheel $4 ; M_{0}-$ momentum of wheel resistance 3 ; $N_{1}, N_{2}, N_{3}$ - pressure forces of individual wheels; $r_{1}=r_{2}=r_{Z}$ and $r_{3}$ - radii of individual wheels; $l_{1}, l_{2}, l_{3}, l_{4}, l_{5}, l_{6}$ - lengths resulting from the MRT geometry.

Next, the procedure of decoupling Lagrange multipliers [3] from the system of equations (8) was applied. A form of equations was obtained that would be convenient for solving the task of simple and inverse dynamics, without the need to determine the values of Lagrange multipliers.

The equations after decoupling Lagrange multipliers have the form:

$$
\begin{aligned}
& {\left[\left(a_{1}+a_{5}\right) \cos ^{2} \varphi+a_{2} \sin ^{2} \varphi+\right.} \\
& \left.-2\left(a_{3}+a_{4}\right) \sin \varphi \cos \varphi+a_{8}\right] \ddot{\alpha}_{3}-a_{6} \sin (\varphi) \ddot{\varphi}+ \\
& +\left[\left(-a_{1}+a_{2}-a_{5}\right) \sin \varphi \cos (\varphi) \dot{\varphi}+\right. \\
& \left.+\left(a_{3}+a_{4}\right)\left(\sin ^{2} \varphi-\cos ^{2} \varphi\right) \dot{\varphi}\right] \dot{\alpha}_{3}= \\
& =M_{\mathrm{N}}+\frac{r_{3}}{l}\left(-M_{\mathrm{S}}+a_{9} \operatorname{sgn}(\dot{\varphi})\right) \sin \varphi+ \\
& -a_{10} \operatorname{sgn}\left(\dot{\alpha}_{3}\right)-a_{11} \cos \varphi \operatorname{sgn}\left(\dot{\alpha}_{3}\right)
\end{aligned}
$$

$$
\frac{1}{r_{3}} a_{6} \ddot{\varphi}-a_{6} \sin (\varphi) \ddot{\alpha}_{3}-a_{6} \cos (\varphi) \dot{\varphi} \dot{\alpha}_{3}=M_{\mathrm{S}}-a_{9} \operatorname{sgn}(\dot{\varphi})
$$

$$
\begin{aligned}
& a_{1}=\left[m_{1}+m_{2}+m_{3}+m_{4}+m_{5}+m_{6}\right] r_{3}^{2} \\
& a_{2}=\left[\left(m_{1}+m_{2}\right) l_{1}^{2}+\left(m_{3}+m_{4}\right) l^{2}+m_{5} l_{5}^{2}+m_{6} l_{6}^{2}+\right. \\
& \left.+I_{\mathrm{x} 1}+I_{\mathrm{x} 2}+I_{\mathrm{x} 3}+I_{\mathrm{z} 4}+I_{\mathrm{z} 5}+I_{\mathrm{z} 6}+\frac{l_{1}^{2}}{r_{\mathrm{z}}^{2}}\left(I_{\mathrm{z} 1}+I_{\mathrm{z} 2}\right)\right] \frac{r_{3}^{2}}{l^{2}} \\
& a_{3}=\left(m_{1}-m_{2}\right) \frac{l_{1} r_{3}^{2}}{l} \\
& a_{4}=\left(I_{\mathrm{z} 1}-I_{\mathrm{z} 2}\right) \frac{l_{1} r_{3}^{2}}{l r_{\mathrm{z}}^{2}} \\
& a_{5}=\left(I_{\mathrm{z} 1}+I_{\mathrm{z} 2}\right) \frac{r_{3}^{2}}{r_{\mathrm{z}}^{2}} \\
& a_{6}=\left(I_{\mathrm{x} 3}+I_{\mathrm{z} 4}\right) \frac{r_{3}}{l} \\
& a_{7}=\left[\left(m_{3}+m_{4}\right) l+m_{5} l_{5}-m_{6} l_{6}\right] \frac{r_{3}^{3}}{l^{2}} \\
& a_{8}=I_{\mathrm{z} 3} \\
& a_{9}=M_{\mathrm{O}} \\
& a_{10}=N_{3} f_{3} \\
& a_{11}=\frac{r_{3}}{r_{\mathrm{z}}}\left(N_{1} f_{1}+N_{2} f_{2}\right)
\end{aligned}
$$
thus:

It was assumed that support wheels 1 and 2 are the same,

$$
\begin{gathered}
m_{1}=m_{2}, I_{\mathrm{x} 1}=I_{\mathrm{x} 2}, I_{\mathrm{y} 1}=I_{\mathrm{y} 2}, I_{\mathrm{z} 1}=I_{\mathrm{z} 2} \\
a_{3}=0, a_{4}=0
\end{gathered}
$$

The system of equations (9) and (10) can be represented in matrix form:

$\mathbf{M}_{22}\left(\mathbf{q}_{2}\right) \ddot{\mathbf{q}}_{2}+\mathbf{C}_{22}\left(\mathbf{q}_{2}, \dot{\mathbf{q}}_{2}\right) \dot{\mathbf{q}}_{2}+\mathbf{F}_{22}\left(\mathbf{q}_{2}, \dot{\mathbf{q}}_{2}\right)=\mathbf{B}_{2}\left(\mathbf{q}_{2}\right) \tau$

Matrices $\mathbf{M}_{22}\left(\mathbf{q}_{2}\right), \mathbf{C}_{22}\left(\mathbf{q}_{2}, \dot{\mathbf{q}}_{2}\right), \mathbf{F}_{22}\left(\mathbf{q}_{2}, \dot{\mathbf{q}}_{2}\right)$ i $\mathbf{B}_{2}\left(\mathbf{q}_{2}\right)$ take the form of:

$$
\mathbf{M}_{22}(\mathbf{q})=\left[\begin{array}{cc}
\left(a_{1}+a_{5}\right) \cos ^{2} \varphi+a_{2} \sin ^{2} \varphi & -\mathrm{a}_{6} \sin \varphi \\
-2\left(a_{3}+a_{4}\right) \sin \varphi \cos \varphi+a_{8} & \frac{l}{r_{3}} a_{6} \\
-a_{6} \sin \varphi &
\end{array}\right]
$$

$\mathbf{C}_{22}\left(\mathbf{q}_{2}, \dot{\mathbf{q}}_{2}\right)=\left[\begin{array}{cc}\left(-a_{1}+a_{2}-a_{5}\right) \sin \varphi \cos (\varphi) \dot{\varphi} & 0 \\ +\left(a_{3}+a_{4}\right)\left(\sin ^{2} \varphi-\cos ^{2} \varphi\right) \dot{\varphi} & 0 \\ -\mathrm{a}_{6} \cos (\varphi) \dot{\varphi} & 0\end{array}\right]$

$$
\mathbf{F}_{22}\left(\mathbf{q}_{2}, \dot{\mathbf{q}}_{2}\right)=
$$

$=\left[\begin{array}{ccc}-\frac{r_{3}}{l} a_{9} \operatorname{sgn}(\dot{\varphi}) \sin (\varphi) & a_{10} \operatorname{sgn}\left(\dot{\alpha}_{3}\right) & a_{11} \cos (\varphi) \operatorname{sgn}\left(\dot{\alpha}_{3}\right) \\ a_{9} \operatorname{sgn}(\dot{\varphi}) & 0 & 0\end{array}\right]$

$$
\begin{aligned}
& \mathbf{B}_{2}\left(\mathbf{q}_{2}\right)=
\end{aligned}
$$

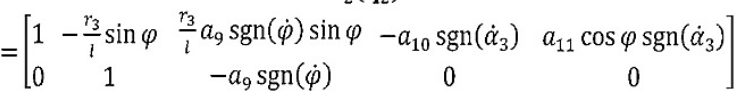

The obtained dynamic equations of MRT motion (14) with decoupled Lagrange multipliers - just like dynamic equations of motion (8) - fulfill all structural properties of mathematical models of mobile circular robots:

- property I: generalized inertia matrix $M_{22}\left(q_{2}\right)$ is a symmetric matrix, positively defined;

- property II: matrix:

$$
\mathbf{S}_{22}\left(\mathbf{q}_{2}, \dot{\mathbf{q}}_{2}\right)=\dot{\mathbf{M}}_{22}\left(\mathbf{q}_{2}, \dot{\mathbf{q}}_{2}\right)-2 \mathbf{C}_{22}\left(\mathbf{q}_{2}, \dot{\mathbf{q}}_{2}\right)=\left[\begin{array}{ll}
S_{1,1} & S_{1,2} \\
S_{2,1} & S_{2,2}
\end{array}\right]
$$


it is an obliquely symmetrical matrix; its elements satisfy the dependences $S_{22 i, j}=0$ for $i=j$, otherwise $S_{22 i, j}=-S_{22 i, j}$;

- property III: dynamic equations of MRT motion in reduced coordinates are linear due to vector $a$, so the system of equations (14) can be written in the form:

$$
\begin{gathered}
\mathbf{M}_{22}\left(\mathbf{q}_{2}\right) \ddot{\mathbf{q}}_{2}+\mathbf{C}_{22}\left(\mathbf{q}_{2}, \dot{\mathbf{q}}_{2}\right) \dot{\mathbf{q}}_{2}+\mathbf{F}_{22}\left(\mathbf{q}_{2}, \dot{\mathbf{q}}_{2}\right)= \\
=\mathbf{B}_{22}\left(\mathbf{q}_{2}\right) \boldsymbol{\tau}_{2}=\mathbf{u}=\mathbf{Y}_{22}\left(\mathbf{q}_{2}, \dot{\mathbf{q}}_{2}, \ddot{\mathbf{q}}_{2}\right) \mathbf{a}
\end{gathered}
$$

where $\mathbf{Y}_{22}\left(\mathbf{q}_{2}, \dot{\mathbf{q}}_{2}, \ddot{\mathbf{q}}_{2}\right)$ is the so-called regression matrix.

\section{Simulation tests}

Simulation studies were carried out, allowing for solving the task of simple and inverse MRT dynamics with the use of the obtained object dynamics model. Simulations were carried out in the MATLAB/SIMULINK computing environment. The set trajectory of the robot's A point is taken into account (fig. 3). The waveforms of the control signals were obtained thanks to the solution of the inverse MRT dynamics problem, using dynamic motion equations (20), written in the following form:

$$
\begin{aligned}
& M_{\mathrm{N}}=\left[\left(p_{1}+p_{3}\right) \cos ^{2} \varphi+p_{2} \sin ^{2} \varphi+p_{5}\right] \ddot{\alpha}_{3}-p_{4} \sin (\varphi) \ddot{\varphi}+ \\
& +\left[\left(-p_{1}+p_{2}-p_{3}\right) \sin \varphi \cos (\varphi) \dot{\varphi}\right] \dot{\alpha}_{3}+ \\
& -\frac{r_{3}}{l}\left(-M_{\mathrm{S}}+p_{6} \operatorname{sgn}(\dot{\varphi})\right) \sin \varphi+p_{7} \operatorname{sgn}\left(\dot{\alpha}_{3}\right)+p_{8} \cos \varphi \operatorname{sgn}\left(\dot{\alpha}_{3}\right) \\
& M_{\mathrm{S}}=\frac{l}{r_{3}} p_{4} \ddot{\varphi}-p_{4} \sin (\varphi) \ddot{\alpha}_{3}-p_{4} \cos (\varphi) \dot{\varphi} \dot{\alpha}_{3}+p_{6} \operatorname{sgn}(\dot{\varphi})
\end{aligned}
$$

where the values of the model parameters, determined on the basis of the robot's CAD model analysis and on the basis of friction and pressure measurements, are:

$$
\begin{gathered}
p_{1}=a_{1}=0,287 \mathrm{kgm}^{2} \\
p_{2}=a_{2}=0,120 \mathrm{kgm}^{2} \\
p_{3}=a_{5}=0,002 \mathrm{kgm}^{2} \\
p_{4}=a_{6}=0,015 \mathrm{kgm}^{2} \\
p_{5}=a_{8}=0,002 \mathrm{kgm}^{2} \\
p_{6}=a_{9}=1,438 \mathrm{Nm} \\
p_{7}=a_{10}=0,832 \mathrm{Nm} \\
p_{8}=a_{11}=0,656 \mathrm{Nm}
\end{gathered}
$$

The waveforms of the control signals were obtained by solving the inverse MRT dynamics problem, using dynamic motion equations (20), stored in the form:

$$
\ddot{\mathbf{q}}_{2}=\mathbf{M}_{22}{ }^{-1}\left(\mathbf{q}_{2}\right)\left[\mathbf{B}_{22}\left(\mathbf{q}_{2}\right) \boldsymbol{\tau}_{2}-\mathbf{C}_{22}\left(\mathbf{q}_{2}, \dot{\mathbf{q}}_{2}\right) \dot{\mathbf{q}}_{2}-\mathbf{F}_{22}\left(\mathbf{q}_{2}, \dot{\mathbf{q}}_{2}\right)\right]
$$

In order to simulate the change of the load transported by the robot, it was assumed that the parameters $p_{1}$ and $p_{2}$ change as follows:

$$
\begin{gathered}
\left.p_{1}(t)=0,2872 \text { dla } t \in<0 ; 40\right) \text { oraz } t \geq 75 \mathrm{~s} \\
\left.p_{1}(t)=0,3512 \text { dla } t \in<40 ; 75\right) \\
\left.p_{2}(t)=0,1195 \text { dla } t \in<0 ; 40\right) \text { oraz } t \geq 75 \mathrm{~s} \\
\left.p_{2}(t)=0,1261 \text { dla } t \in<40 ; 75\right)
\end{gathered}
$$

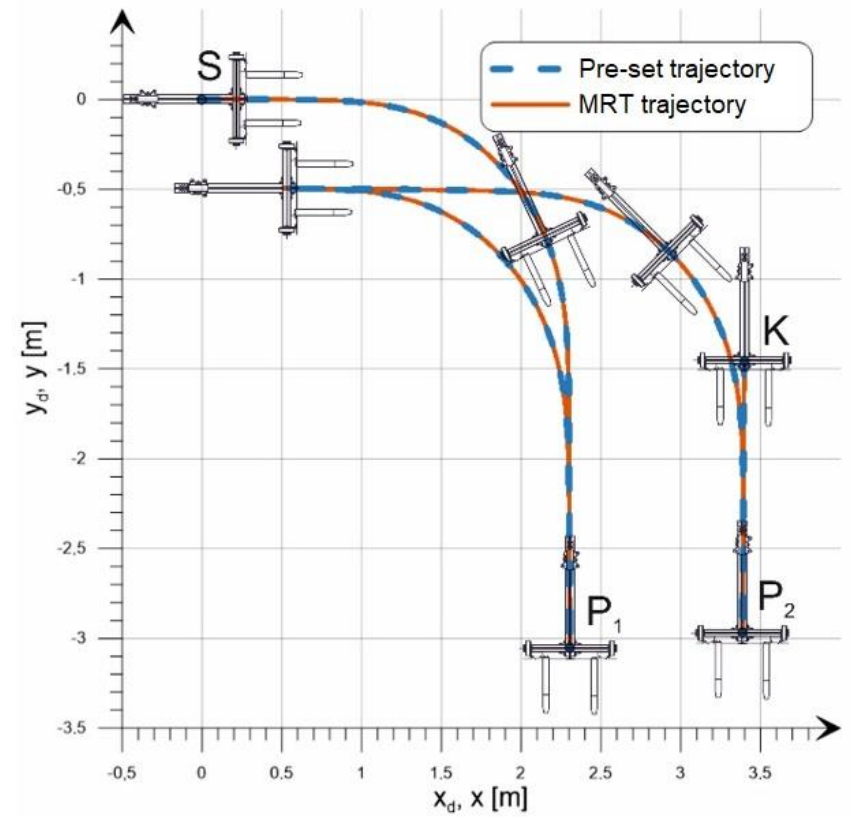

Fig. 3. Trajectory of the robot's $A$-point - given and received from the solution of the task of simple dynamics

This corresponds to the transport task of the load with the mass $m_{\mathrm{L}}=10 \mathrm{~kg}$. The course of parameters $p_{1}$ and $p_{2}$ over time is shown in fig. 4 and fig. 5.

Parameter values increase when the robot is at point $P_{1}$ of the given path, and return to the nominal value when the robot is at the point $P_{2}$, which corresponds to the load of the MRT lift with the mass of the transported load and removal of additional load at appropriate moments.

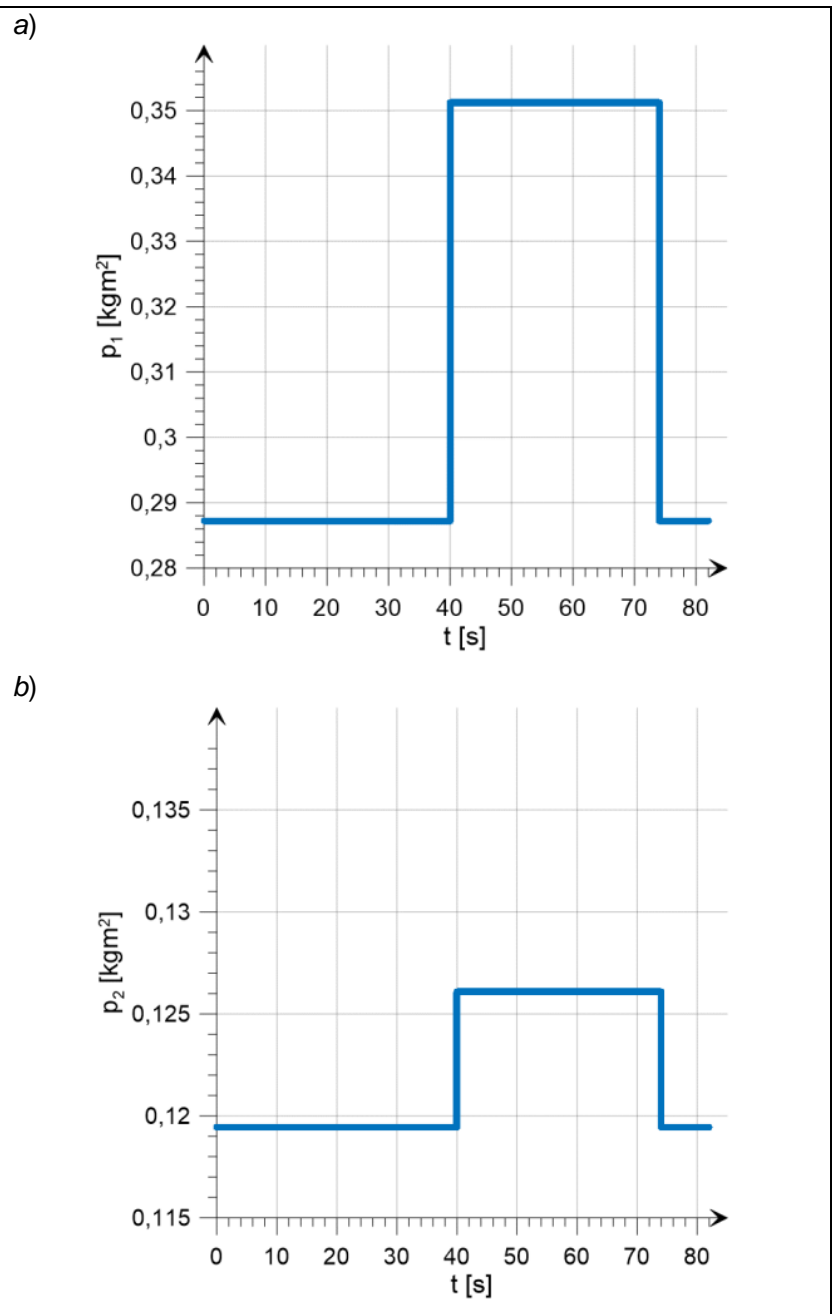

Fig. 4. Course of values: a) parameter $p_{1}, b$ ) parameter $p_{2}$ 


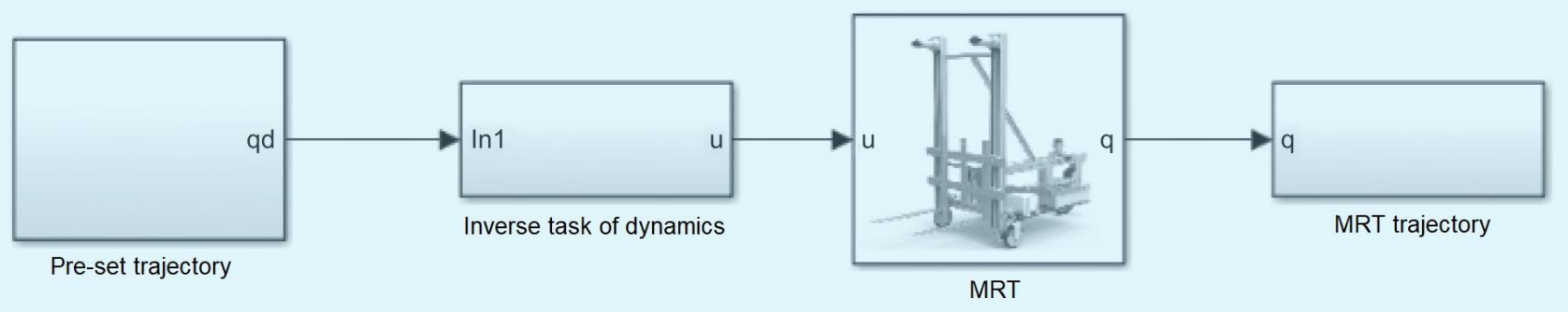

Fig. 5. Diagram of the simple task model and inverse MRT dynamics

Fig. 6. Course of the drive torque: a) wheel $3-M_{N}$, b) steering wheel $4-M_{\mathrm{s}}$
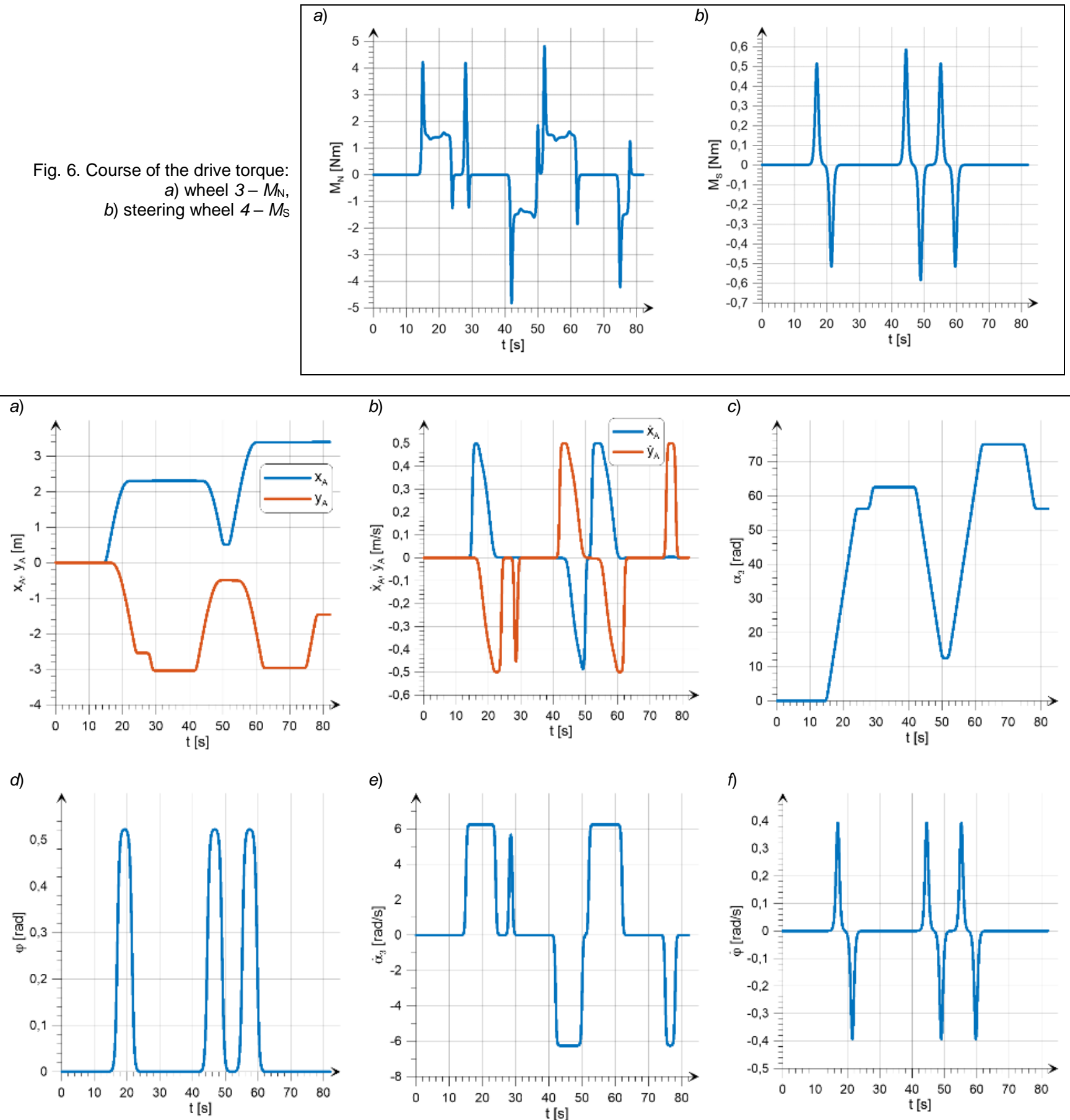

Fig. 7. Runs: a) coordinates of robot $A$ point, $b$ ) projection of speed vector $A$ on axes $x y, c$ ) angle of rotation of drive wheel $\left.\alpha_{3}, d\right)$ steering angle $\varphi, e$ ) values of angular velocity of drive wheel $\left.\dot{\alpha}_{3}, f\right)$ the angular speed values of the steering wheel $\varphi$

Based on the adopted relationships, a simulation model of the inverse and simple MRT dynamics was built in the MATLAB/SIMULINK computing environment, shown schematically in fig. 5 .

The solution of the inverse dynamics task allowed to obtain the courses of values of the $M_{N}$ and $M_{s}$ driving moments necessary for the implementation of the set trajectory of the robot's A point.

During the movement of the robot with the load during start-up and braking, the values of the driving torque of the wheel 3 are greater than when the robot moves without load. Calculated values of drive moments were introduced to the 
task of simple MRT dynamics and a realized trajectory was determined, which was compared with the trajectory (shown in fig. 3). The movement path of the robot's A point, obtained from the solution of the task of simple dynamics, is similar to the given path of movement. Fig. 7a shows the course of the coordinates of point $A$, and in fig. $7 b$ - the course of projections of the velocity vector $A$ on the $x$ and $y$ axes of the stationary reference system. In fig. $7 c-d$, the angles of rotation of the $\alpha_{3}$ driving wheel and steering wheel are presented, while in fig. $7 e-f-$ the angular velocity values of the drive wheel and steering wheel $\varphi$ are shown.

\section{Conclusions}

In the work, the model of MRT dynamics was synthesized thanks to the determination of dynamic equations of motion of the system with nonholonomic constraints, which allow solving the task of simple and inverse dynamics without the need to determine the values of Lagrange multipliers. The parameters of the MRT dynamics model were evaluated based on experimental studies and analysis of the robot's CAD models. The determined parameters were used in the simulation of simple and inverse dynamics.

The presented MRT dynamics model will allow for the synthesis of robot tracking algorithms and the simulation of its motion in changing operating conditions.

\section{REFERENCES}

1. Domorecki A., Krykowski K. „Silniki BLDC - Klasyczne metody sterowania". Zeszyty Problemowe. Maszyny Elektryczne. 72 (2005): pp. 155-159.

2. Trojnacki M. „Mobilne roboty lądowe w transporcie”. Logistyka. 4 (2015): pp. 6273-6283.

3. Giergiel M.J., Hendzel Z., Wiesław Ż. „Modelowanie $i$ sterowanie mobilnych robotów kołowych". Warszawa: Wydawnictwo Naukowe PWN, 2013.

4. Żylski W., Gierlak P. „Sterowanie ruchem nadążnym robotów manipulacyjnych". Rzeszów: Oficyna Wydawnicza Politechniki Rzeszowskiej, 2008.

5. Żylski W. „Kinematyka i dynamika mobilnych robotów kołowych". "Rzeszów: Oficyna Wydawnicza Politechniki Rzeszowskiej, 1996.

6. Żylski W. "Opis ruchu 3 - kołowego mobilnego robota”. Materiały "XV Ogólnopolskiej Konferencji Naukowo-Dydaktycznej Teorii Maszyn i Mechanizmów, Białystok Białowieża 1996, p. 489.

7. Hendzel Z. „Sterowanie ruchem nadążnym mobilnych robotów kołowych". "Rzeszów: Oficyna Wydawnicza Politechniki Rzeszowskiej, 1996.

8. Spong M.W., Vidyasagar M. „Dynamika i sterowanie robotów”. Wydawnictwo Naukowo Techniczne, 1997.

9. Szuster M., Obal P. „Kinematyka Mobilnego Robota Transportowego". Przegląd Mechaniczny. 2 (2017): pp. 24-28.

Translation of scientific articles, their computer composition and publishing them on the website www.mechanik.media.pl by original articles in Polish is a task financed from the funds of the Ministry of Science and Higher Education designated for dissemination of science. 